\title{
PAPERS
}

\section{Effects of cisapride on gastric emptying of oil and aqueous meal components, hunger, and fullness}

\author{
K L Jones, M Horowitz, B I Carney, W M Sun, B E Chatterton
}

\begin{abstract}
To evaluate the effects of cisapride on gastric emptying of extracellular fat and hunger and fullness 10 volunteers consumed a meal consisting of $60 \mathrm{ml}$ technectium-99m $\left({ }^{99 m} \mathrm{Tc}\right)-\mathrm{V}$-thiocyanate labelled olive oil and $290 \mathrm{ml}$ indium $113 \mathrm{~m}$ ( ${ }^{113 \mathrm{~m} I n)}$ labelled soup after taking cisapride (10 mg four times daily orally) and placebo, each for four days, in randomised, double blind fashion. Gastric emptying was quantified scintigraphically. Hunger and fullness before and after the meal were evaluated using visual analogue scales. Cisapride accelerated gastric emptying of oil and aqueous components by reducing the lag phase mean (SEM) $(20.3(7 \cdot 0) \mathrm{min} v 40.7(4 \cdot 1) \mathrm{min}$ $(p<0.05)$ for oil and $4.1(2.5)$ min $v 10.0$ (3.1) min $(p<0.05)$ for aqueous $)$. Cisapride had no effect on the post-lag emptying rate of oil. Treatment with cisapride was associated with reduced retention of oil in the proximal stomach $(p<0.05)$. Subjects were more hungry before ingestion of the meal while receiv-

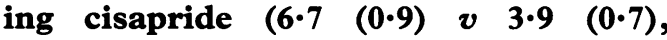
$p<0.001)$. The scores for hunger at 120 and 180 minutes were inversely related to gastric emptying of oil on both cisapride $(r>-0.62, p<0.05)$ and placebo $(r>-0.86$, $p<0.001)$. Fullness increased after the meal while receiving placebo $(\mathbf{p}<0.01)$, but not cisapride and postprandial fullness was less with cisapride at $(30 \mathrm{~min}$; $0.4(0.3)$ v $3.3(1.0), \quad \mathrm{p}<0.05)$. With placebo, but not cisapride, the score for fullness at 15 minutes was inversely related to emptying of the aqueous phase $(r=-0.68, p<0.05)$. These results show that in normal volunteers after ingestion of an oil/aqueous meal: (a) postprandial hunger is inversely related to gastric emptying of oil, while fullness is inversely related to gastric emptying of the aqueous phase, (b) cisapride affects the intragastric distribution and accelerates gastric emptying of both oil and aqueous meal components, and (c) cisapride increases preprandial hunger and reduces postprandial fullness.

(Gut 1996; 38: 310-315)
\end{abstract}

Keywords: cisapride, gastric emptying, hunger, fullness, oil, water.
Disordered gastric emptying, particularly delayed emptying, occurs frequently and may be associated with gastrointestinal symptoms such as nausea, abdominal pain, and vomiting. ${ }^{1}$ In normal subjects gastric ${ }^{2}{ }^{3}$ and small intestinal ${ }^{4}$ administration of fat retard gastric emptying. In patients who suffer from unexplained upper abdominal symptoms, gastric emptying may be exacerbated by intake of high fat meals and in patients with non-ulcer dyspepsia, delay in gastric emptying is more commonly seen with nutrient rich (high fat) than with bland meals. ${ }^{5}$ The intragastric distribution of fatty meals is also frequently abnormal in patients with non-ulcer dyspepsia. ${ }^{6}$

The most effective therapeutic approach to the treatment of symptomatic gastroparesis is the use of drugs designed to increase the rate of gastric emptying ${ }^{1}$ and cisapride is arguably the gastrokinetic drug of first choice. ${ }^{7}$ Cisapride has been shown to abolish the slowing of gastric emptying induced by giving fat immediately before a meal in normal subjects, ${ }^{23}$ but the effects of cisapride or other prokinetic agents on gastric emptying of fat have not been evaluated to our knowledge. Recent studies performed by ourselves and others show that gastric emptying of extracellular fat is influenced by both its intragastric distribution, and feedback from receptors in the small intestine. ${ }^{8-11}$ There is evidence that in therapeutic doses cisapride does not have the capacity to overcome small intestinal feedback regulation of normal gastric emptying, ${ }^{7}$ but the effects of cisapride on intragastric meal distribution have not been assessed.

While cisapride accelerates gastric emptying and relieves symptoms in most forms of gastroparesis, there is a poor relation between the magnitude of the improvements in emptying and symptoms, ${ }^{7}$ suggesting that factors unrelated to normalisation of gastric emptying may contribute to the beneficial effects of cisapride on symptoms. The controls of appetite in humans are poorly understood, but it is clear that signals from the gastrointestinal tract are important. ${ }^{12}$ Gastric distension is well recognised as a signal for satiety ${ }^{13}$ and recent studies suggest that postprandial hunger is also related to the extent of small intestinal nutrient exposure. ${ }^{814}$ Cisapride is devoid of antidopaminergic and central antiemetic properties and psychological effects. ${ }^{7} 15$ Perhaps because of these reasons the effects of cisapride on appetite have not been formally evaluated. 
We have now used a specific radioisotopic marker of extracellular fat to evaluate the,effects of cisapride on gastric emptying and intragastric distribution of oil and aqueous meal components and appetite in normal subjects.

\section{Methods}

\begin{abstract}
Subjects
Ten healthy volunteers (one male, nine female), mean age 22 years (range 18-28) and mean body weight $67 \cdot 2 \mathrm{~kg}$ (range 39.6-98.4) had two measurements of gastric emptying, hunger and fullness, once after taking cisapride and the other after taking placebo. None of the subjects had a history of gastrointestinal disease or was taking medication known to influence gastrointestinal motility. Written informed consent was obtained from each subject and the study was approved by the Human Ethics Committee of the Royal Adelaide Hospital.
\end{abstract}

\section{Protocol}

Each of the volunteers had measurements of gastric emptying, hunger, and fullness on two separate days after receiving cisapride $(10 \mathrm{mg}$ four times daily) or placebo, both given as tablets in random, double blind, crossover fashion. Cisapride and placebo tablets were identical in appearance and taste. For four days before each of the two study days each subject took one tablet four times a day (before meals). After the first study day, each subject entered a drug-free 'washout' phase of 7 to 10 days and then received the alternate treatment in identical fashion. The last tablet was taken about two hours prior to the gastric emptying study. Remaining tablets were returned on each of the study days. The test meal was consumed within five minutes at about $1000 \mathrm{am}$ after an overnight fast (14 hours for solids and 12 hours for liquids) with the subject seated in front of a scintillation camera. ${ }^{8}$ The meal comprised $60 \mathrm{ml}$ olive oil (Faulding, South Australia) labelled with $20 \mathrm{MBq}$ technetium$99 \mathrm{~m}\left({ }^{99 \mathrm{~m}} \mathrm{Tc}\right)-(\mathrm{V})$-thiocyanate and $290 \mathrm{ml}$ of low nutrient beef consomme soup (Campbell's Soup, Australia) labelled with $20 \mathrm{MBq}$ indium $113 \mathrm{~m}$ (113m In)-diethylenetriamine-pentaacetic acid (DTPA). The meal was heated to $45^{\circ} \mathrm{C}$ immediately before ingestion ${ }^{8}$ and the oil was mixed gently with the soup immediately before and during consumption. The energy content of the oil-soup mixture ( $7 \mathrm{~g}$ protein, $52 \mathrm{~g}$ fat) was 505 . kcal (of which $475 \mathrm{kcal}$ were contained in the oil). Feelings of hunger and fullness were recorded on a validated visual analogue scale immediately before and at 15 , $30,60,90,120,150,180,210$, and 240 minutes after ingestion of the test meal. ${ }^{8}$

\section{Measurement of gastric emptying}

The preparation of the test meal has been described previously. ${ }^{16}$ Radionuclide data for both isotopes, were acquired on computer for at least 180 minutes in each of the studies, starting immediately after ingestion of the liquid meal and were subsequently corrected for subject movement, Compton scatter, radionuclide gamma ray attenuation, and radionuclide decay. ${ }^{17}$ Correction for attenuation was done using factors derived from a lateral image of the stomach. ${ }^{17} \mathrm{~A}$ region of interest (ROI) was drawn around the total stomach, which was then divided into proximal and distal regions - the proximal region corresponding to the fundus and proximal corpus and the distal region representing the distal corpus and antrum. Gastric emptying curves for total, proximal, and distal stomach (expressed as $\%$ retention over time) were derived ${ }^{8}$ and several parameters were obtained from these curves for subsequent statistical analysis. For the total stomach these were the lag phase, before any of the oil or aqueous components started to empty from the stomach, and the amount of the oil and aqueous meal components that remained in the stomach at 15,30 , 60,120 , and 180 minutes. ${ }^{8} 11$ The lag phase was determined visually as the frame preceding that in which activity was seen in the proximal small intestine. ${ }^{17}$ For the oil component of the meal the rate of emptying, expressed as $\% / \mathrm{min}$ between the end of the lag phase and 180 minutes, was also calculated. ${ }^{16} 17$ The $50 \%$ emptying time (T50) for the total stomach was derived for the aqueous, but not the oil phase, as in some subjects the T50 for oil was not reached during the study period. For the proximal and distal stomach, the retention of isotope at $15,30,60,120$, and 180 minutes (expressed as a percentage of the maximum count in the total stomach) was calculated. The $50 \%$ emptying time for the proximal stomach (PT50) and the maximum content of the distal stomach were also derived. ${ }^{8}$ The maximum content of the distal stomach was defined as the maximum counts in the distal stomach after meal ingestion. ${ }^{8}$ Retrograde movement of oil or aqueous phases from the distal into the proximal stomach was defined as a rise in proximal stomach counts $\geqslant 10 \%$ associated with a fall in distal stomach counts of $>10 \% .^{16}$ The number of episodes of retrograde movement in each subject was counted.

\section{Assessment of hunger and fullness}

Subjective ratings of hunger and fullness were assessed by marking $100 \mathrm{~mm}$ long visual analogue lines, which were subsequently scored by one of the authors (KJ). Full details of this questionnaire, which evaluates a range of sensations including anxiety, sleepiness, desire to eat, hunger, quantity of food you could eat, nausea, fullness, dizziness, indigestion, stomach rumbles, presence of a headache, and thirst have been published previously. ${ }^{18}$

\section{Statistical analysis}

Data were evaluated using repeated measures analysis of variance (ANOVA) and are shown as mean values (SEM). The factors for which the ANOVAs accounted included treatment (cisapride or placebo), time after meal ingestion, sequence (order), meal component (oil or 
Figure 1: Retention of oil and aqueous meal components in total, proximal, and distal stomach regions of interest. Data are mean values (SEM). * $p<0.05$, $\star \star p<0.01$ placebo $\mathrm{v}$ cisapride.

Oil

Aqueous
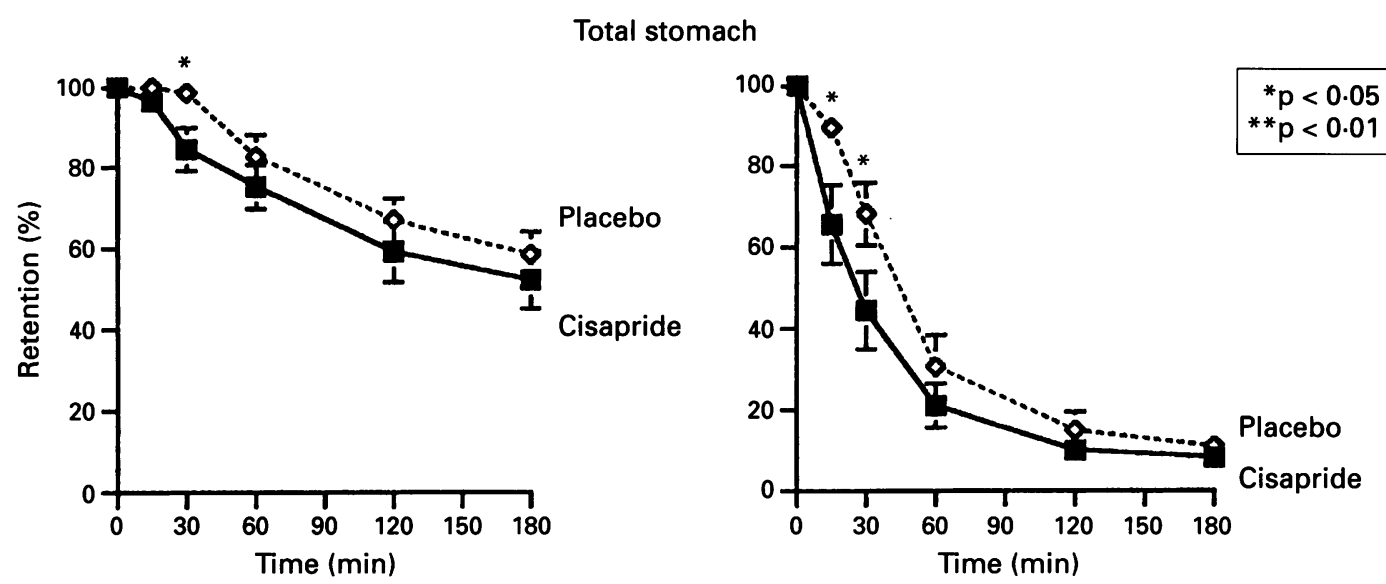

Proximal stomach
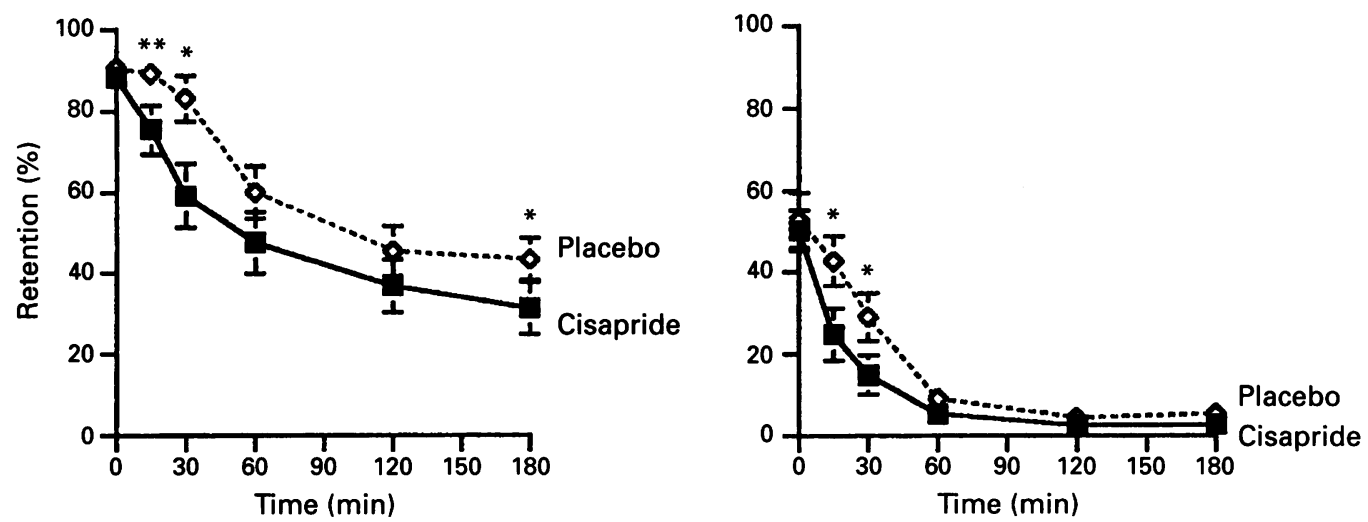

Distal stomach

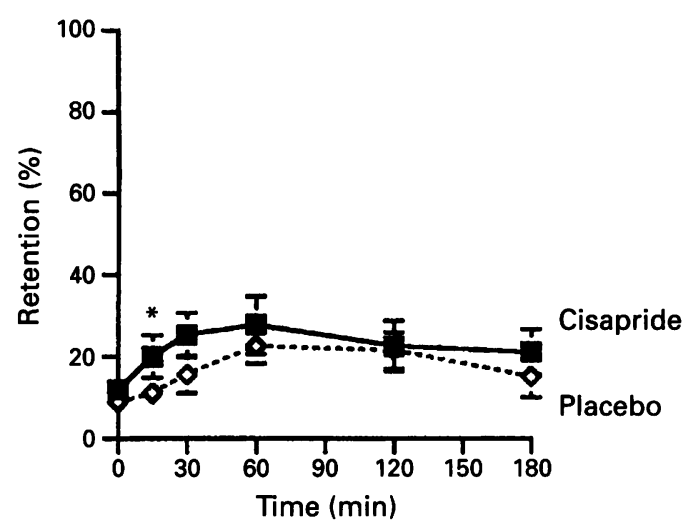

aqueous), and region of the stomach (total, proximal, distal). Gastric emptying curves show the retention of isotope at $0,15,30,60$, 120 , and 180 minutes. The relations between gastric emptying and intragastric distribution of both oil and aqueous meal components and subjective ratings of hunger and fullness were evaluated using linear regression analysis. A $p$ value of $<0.05$ was used to show statistical significance in all analyses.

\section{Results}

All 10 subjects tolerated the study well and, as assessed by tablet counts, complied with medication. Six subjects reported adverse effects including nausea (two subjects), headache (two subjects), and more frequent bowel actions (five subjects) while taking

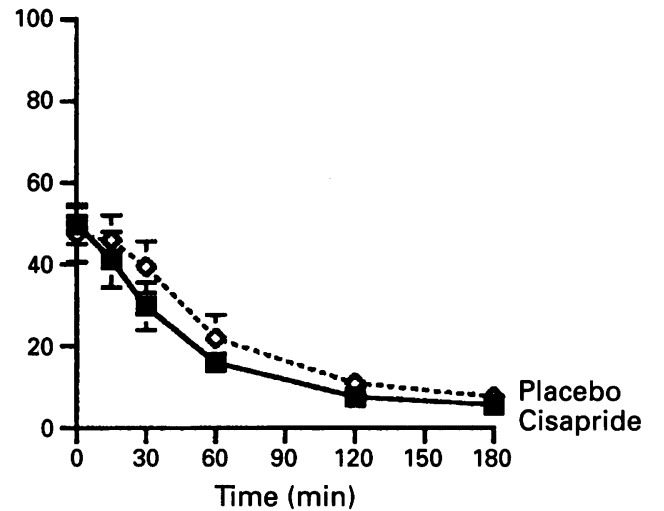

cisapride. In all cases these symptoms were mild and disappeared within a week after taking the last tablet. One subject had a mild headache while taking placebo, but no other adverse effects were reported. The effect of cisapride on the sensation of fullness was analysed using the first period data only, as there was an order effect.

GASTRIC EMPTYING OF OIL AND AQUEOUS MEAL COMPONENTS

\section{Total stomach}

Oil component - emptying of oil approximated a linear pattern after an initial lag phase. ${ }^{16}$ When subjects were taking cisapride, the lag phase was shorter $(20.3(7 \cdot 0)$ min $v$ $40.7(4.1) \mathrm{min} ; \mathrm{p}<0.05)$ and the retention of 


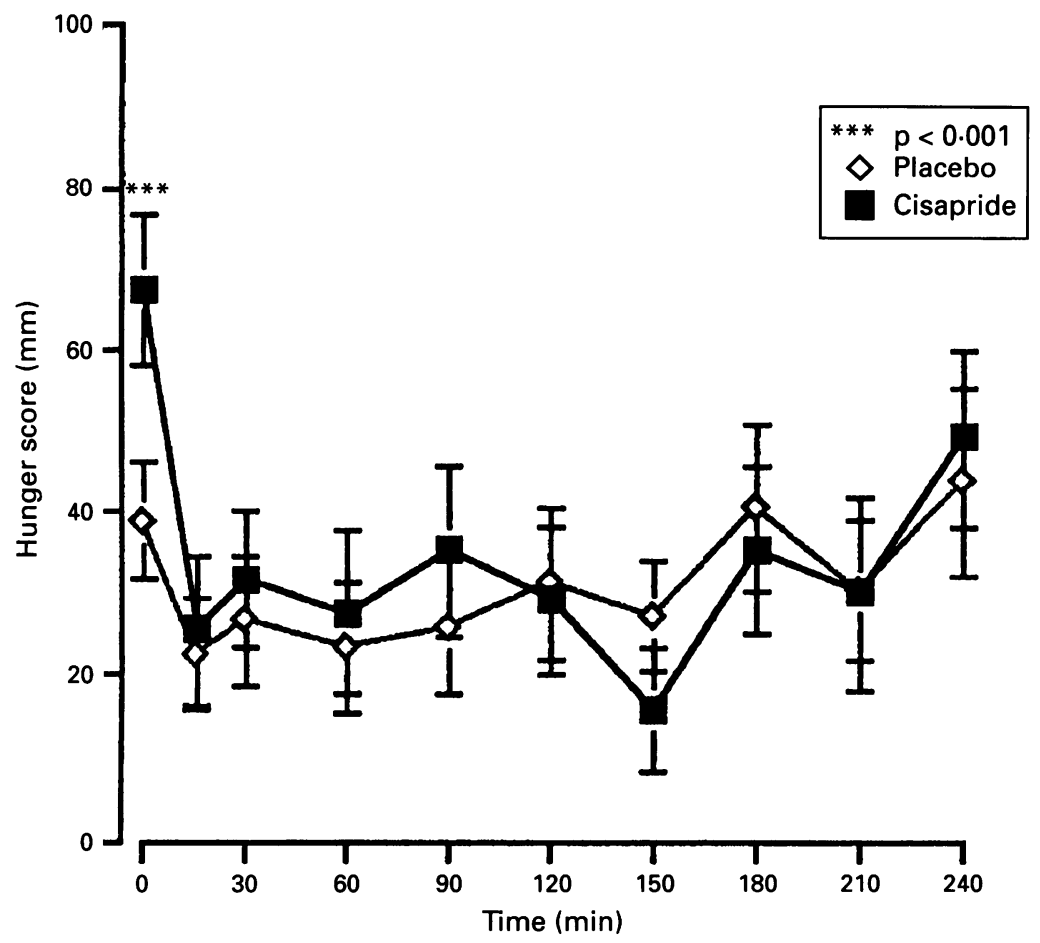

Figure 2: Scores for hunger before and after meal ingestion. Data are mean values (SEM). ${ }_{\star \star \star} p<0.001$ placebo $\mathrm{v}$ cisapride. oil in the stomach at 30 minutes was less $(84.4$ $(5.4) \% v 98.6(1.2) \%$; $<<0.05)$ (Fig 1) than when taking placebo. There was no effect of cisapride on the emptying rate of oil after the lag phase $(0.30 \quad(0.04) \% / \mathrm{min} v 0.29$ $(0.04) \% / \mathrm{min} ; \mathrm{NS})$.

Aqueous component - emptying of the aqueous component from the stomach approximated a monoexponential function after a short lag phase. The lag phase was shorter after cisapride $(4.1(2.5)$ min $v 10.0(3.1) \mathrm{min}$; $\mathrm{p}<0.05)$ compared with placebo. The amount of the aqueous component remaining in the stomach at 15 minutes and 30 minutes was less $(p<0.05)$ with cisapride (Fig 1). There was a non-significant trend for the T50 to be shorter with cisapride $(28 \cdot 7(6 \cdot 0) \min v 50 \cdot 8(9 \cdot 2)$ $\min ; \mathrm{p}=0.076$ ).

\section{Intragastric meal distribution}

During treatment with both cisapride and placebo there was more of the oil than the aqueous component retained in the proximal stomach $(p<0.001)$ and in all studies there was evidence of a 'midgastric band' - a band of decreased radioactivity separating the proximal and distal stomach. ${ }^{8}$ Retrograde movement of the oil from the distal to the proximal stomach in the 180 minutes after ingestion of the meal was evident in all subjects, with both cisapride and placebo. There was a non-significant trend for a greater number of episodes of retrograde movement per subject in those taking cisapride (3.5 (0.65) v 2.4 (0.58); $\mathrm{p}=0.063)$. Retrograde movement of the aqueous phase from distal to proximal stomach was not evident in any study.

Oil component - there was less oil in the proximal stomach at 15 and 30 minutes $(\mathrm{p}<0.05$ for both) with cisapride and at 15 minutes there was more oil in the distal stomach $(p<0.05)$ (Fig 1) when compared with placebo. The effects of cisapride on both the proximal stomach T50 (117.4 (27.9) $\min v$
$145 \cdot 1(32 \cdot 5) \mathrm{min} ; \mathrm{NS})$ and the maximum content of the distal stomach $(44.9(5 \cdot 1) \% v 40 \cdot 4$ $(6 \cdot 4) \%$; NS) did not differ from placebo.

Aqueous component - there was less of the aqueous meal component in the proximal stomach at 15 minutes and 30 minutes $(\mathrm{p}<0.05)$ and the proximal stomach T50 was shorter (5.9 (2.5) min $v 14.3(5.3) \mathrm{min}$; $\mathrm{p}<0.05)$ with cisapride compared with placebo. There was no significant difference in the retention of the aqueous component in the distal stomach at any time point or the maximum content of the distal stomach $(55.0$ $(5 \cdot 8) \%$ v $51.5(6.2) \%$; NS) between cisapride and placebo (Fig 1).

Relations between retention in the total, proximal, and distal stomach

Oil component - there were significant relations between the amounts of oil in the proximal and total stomach at 120 minutes with both cisapride $(r=0.61, \mathrm{p}<0.05)$ and placebo $(r=0.74, \mathrm{p}<0.01)$. There was a significant inverse relation between total stomach and distal stomach content at 30 minutes with placebo $(r=-0.80, \mathrm{p}<0.01)$ but not cisapride $(r=-0.08$; NS).

Aqueous component - there was a significant linear relation between the amount of the aqueous component in the proximal stomach at 30 minutes and the total stomach T50 with cisapride $(r=0.86, \mathrm{p}<0.001)$, but not placebo $(r=0.32 ; \mathrm{NS})$. There was no relation between the distal and total stomach retention or T50 with either cisapride or placebo.

\section{Hunger and fullness}

Hunger - before ingestion of the meal the score for hunger was higher $(p<0.001)$ when subjects were taking cisapride (Fig 2). There was a decrease in hunger 15 minutes after the meal with both cisapride $(p<0.0001)$ and placebo $(p<0.05)$ and no significant difference between the hunger ratings for the two groups.

Fullness - increased 15 minutes after the meal when subjects had taken placebo $(p<0.001)$ but not significantly with cisapride $(p=0.59 ; N S)$. The scores for fullness were lower with cisapride than placebo at 15,30 , and 90 minutes ( $p<0.05$ for all) (Fig 3 ).

\section{Relation between hunger and fullness and gastric emptying}

Oil component - at both 120 and 180 minutes, hunger was directly related to the retention of oil in the stomach with both placebo $(r \geqslant 0.86$, $\mathrm{p}<0.001)$ and cisapride $(r \geqslant 0.62, \mathrm{p}<0.05)$ (Fig 4 ) - that is, subjects were less hungry when more of the oil had emptied from the stomach. There were no significant relations between fullness and gastric emptying of oil with either cisapride or placebo.

Aqueous component - the score for fullness at 15 minutes with placebo was directly related to both the duration of the lag phase $(r=0.65$, $\mathrm{p}<0.05)$ and the retention at 30 minutes $(r=0.68, \mathrm{p}<0.05)-$ that is, subjects felt more 


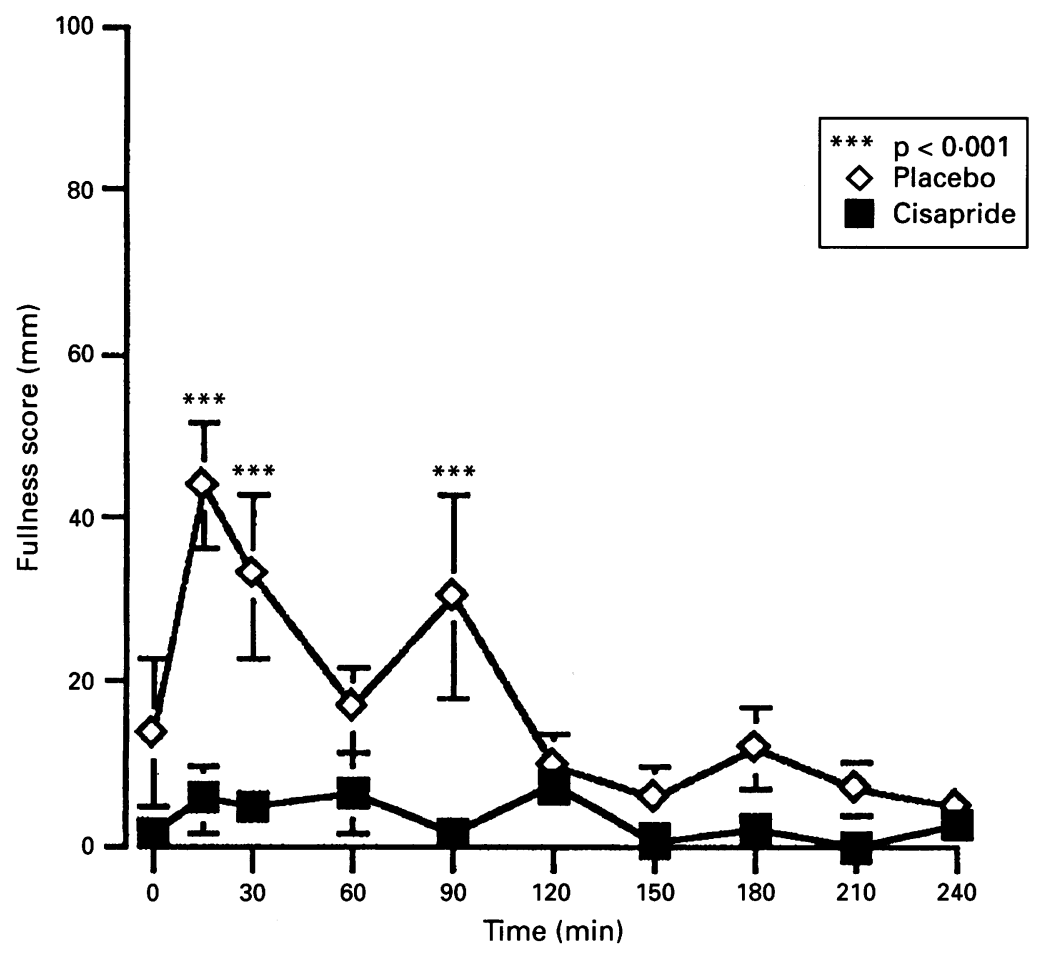

Figure 3: Scores for fullness before and after meal ingestion for the first test day. Data are mean values (SEM). ${ }^{\star \star \star}{ }^{*}<0.001$ placebo $\mathrm{v}$ cisapride.

Figure 4: Relation between the score for hunger at 180 minutes and the amount of oil remaining in the stomach at 180 minutes with placebo and cisapride.

full when gastric emptying of the aqueous phase was slower. In subjects taking cisapride there was no significant relation between fullness and gastric emptying.

\section{Discussion}

Our results show that in normal subjects, after ingestion of a meal comprising oil and aqueous components (a) cisapride affects the intragastric distribution of the oil component and accelerates gastric emptying of both oil and aqueous meal components, (b) postprandial hunger is inversely related to gastric emptying of oil, while fullness is inversely related to gastric emptying of the aqueous phase, and (c) cisapride increases preprandial hunger and reduces postprandial fullness.

It is well known that gastric emptying of high fat meals is slower than that of low nutrient meals. At body temperature most extracellular fat is in the oil phase. The intragastric distribution of oil is influenced by the composition and volume of other meal components and posture ${ }^{8-10}$ For example, because of its lower density, oil will float towards the gastric outlet in the decubitus position and away from it in the sitting position. ${ }^{8}$ The most

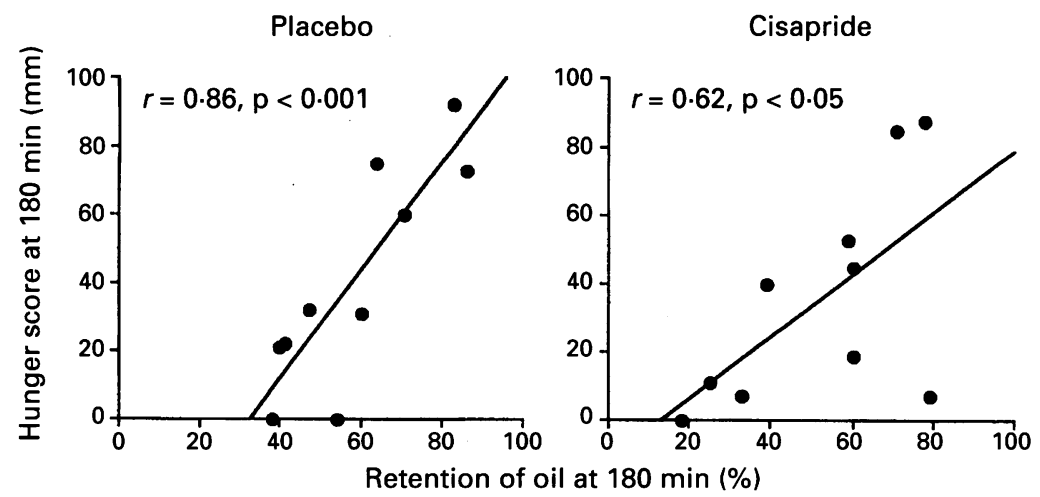

important factor regulating gastric emptying of oil in normal subjects, however, is the interaction of lipolytic products with receptors in the small intestinal lumen. ${ }^{910}$ As a result of diminished small intestinal feedback, gastric emptying of oil is faster than normal in patients with pancreatic insufficiency. ${ }^{11}$ Our finding that gastric emptying of oil was accelerated by cisapride is consistent with previous studies. ${ }^{23}$ Stacher et al reported that the retardation of gastric emptying of a semisolid meal by giving a fat preload to normal subjects was abolished by both intravenous ${ }^{2}$ and rectal $^{3}$ administration of cisapride, while in dogs, Janisch et al (XI International symposium on gastrointestinal motility, 1987) found that gastric emptying of a barium meal containing $20 \mathrm{ml}$ olive oil was also accelerated by cisapride. It should, however, be recognised that the magnitude of the increase in gastric emptying of oil induced by cisapride that we observe was small and reflected a reduction in the duration of the lag phase, with no significant change in the post-lag emptying rate. This last finding is compatible with the concept that cisapride, at least in doses used therapeutically, does not overcome the physiological feedback mechanisms that regulate gastric emptying of nutrient containing meals in normal subjects. ${ }^{7}$ In particular, cisapride has little or no effect on normal gastric emptying of solid meals. ${ }^{7}$ The reduction in the lag phase for oil and aqueous components of the meal by cisapride probably reflects the more rapid movement of oil from the proximal to the distal stomach.

A number of studies have evaluated the motor mechanisms responsible for the modest increase in gastric emptying caused by cisapride in normal subjects ${ }^{7920}$ and the more pronounced acceleration in patients with gastroparesis. ${ }^{2122}$ The rate of gastric emptying is dependent on the relations between contractions generated by the proximal stomach, antrum, pylorus, and proximal small intestine, so that no motor mechanism should be considered to exert the dominant control, either propulsive or retardant over normal gastric emptying. ${ }^{23} \mathrm{We}$, and others, have shown that cisapride affects antral and pyloric motility, including the organisation of antral pressure waves, in both normal subjects and patients with gastroparesis. ${ }^{71921}$ Our finding that the retention of both oil and aqueous phases in the proximal stomach was less with cisapride suggests that cisapride also affects proximal stomach motility. ${ }^{24}$ Gastric emptying is predominantly pulsatile, rather than continuous, and there is considerable variation in the characteristics of flow pulses (volume and frequency) from one contraction cycle to the next. ${ }^{25} 26$ This variability seems to result mainly from changes in the temporal and spatial patterning of tone and active lumen occlusion in different regions of the stomach and small intestine. ${ }^{23}$ Therefore, while we found that cisapride had no effect on the overall emptying rate of oil or aqueous phases, we cannot exclude changes in the characteristics of individual flow pulses. ${ }^{26}$ 
Although the mechanisms responsible for the regulation of appetite in humans are complex it is clear that signals from the gastrointestinal tract influence both hunger and satiation. Because our test meal comprised discretely labelled oil and aqueous components and the aqueous phase had a low nutrient content, the relations between hunger and fullness and gastric emptying could be more fully evaluated than in previous studies. The finding that postprandial hunger in normal subjects is inversely related to gastric emptying of oil is consistent with our previous study ${ }^{8}$ and shows that interaction with small intestinal receptors (perhaps via the subsequent stimulation of vagal efferents or release of cholecystokinin, or both) contributes to the effects of fat on satiation. 142728 The results of our previous study in patients with pancreatic insufficiency suggest that lipolysis may be required for small intestinal inhibition of hunger by fat. ${ }^{11}$ The finding that postprandial fullness was related to the amount of the aqueous phase in the stomach is novel but consistent with previous studies ${ }^{11}$ and compatible with the concept that gastric distension leads to satiety, ${ }^{13}$ as the aqueous phase comprised most of the volume of our test meal. The intragastric mechanisms triggering satiety are uncertain. It is, however, of interest that in general patients with non-ulcer dyspepsia have a wider gastric antrum than normal, both fasting and postprandially. ${ }^{29}$ This last finding has been postulated to result from disordered proximal stomach tone, with subsequent increased antral distension.

The findings that cisapride increased preprandial hunger and reduced postprandial fullness are novel, and because of their potential important clinical relevance require confirmation. An evaluation of hunger was included in the study of Stacher et $a l^{15}$ but the results were not given. Presumably no effect of cisapride on appetite was detected. In an unpublished study (Tomita et al), however, an improvement in appetite was seen in patients after partial gastrectomy treated with cisapride. Current understanding of the aetiology of gastrointestinal symptoms in patients with gastroparesis and the factors responsible for symptomatic improvement resulting from prokinetic treatment is limited, but it is clear that neither can be totally attributed to the rate of gastric emptying in itself. $^{17}$ While the mechanisms mediating the effects of cisapride on fullness are uncertain it seems unlikely that the reduction in fullness with cisapride compared with placebo is accounted for by a decrease in intragastric volume, as the overall acceleration of gastric emptying by cisapride was modest. More plausible alternatives are that effects of cisapride on proximal stomach or antral tone, or intragastric meal distribution, perhaps by leading to changes in afferent sensory feedback, are important. These issues warrant exploration in future studies.

This work was supported by a grant from the National Health and Medical Research Council of Australia and Janssen-Cilag, Australia. We wish to thank $\mathrm{Dr} M$ Verlinden of Janssen Research Foundation for her helpful comments, Miss T Piscioneri for typing this manuscript, and Miss Kristen Wilson for statistical advice.
1 Horowitz M, Dent J. Disordered gastric emptying: mechanical basis, assessment and treatment. Baillieres Clin Gastroenterol 1991; 5: 371-407.

2 Stacher G, Bergmann H, Gaupmann G, Schneider C, Kugi A, Hobart J, et al. Fat preload delays gastric emptying

reversal by cisapride. Br fClin Pharmacol 1990; 30: 839-45.

Stacher G, Granser GV, Bergmann H, Kugi A, Stacher Janotta G, Hobart J. Slow gastric emptying induced by high fat content of meal accelerated by cisapride
tered rectally. Dig Dis Sci 1991; 36: 1259-65.

4 Heddle R, Collins PJ, Dent J, Horowitz M, Read NW, Chatterton B, et al. Motor mechanisms associated with slowing of the gastric emptying of a solid meal by an intraduodenal lipid infusion. $\mathcal{F}$ Gastroenterol Hepatol 1989 ; 4: 437-47.

5 Houghton LA, Mangnall YF, Dwivedi A, Read NW. Sensitivity to nutrients in patients with non-ulcer dyspepsia. Eur f Gastroenterol Hepatol 1993; 5: 109-13.

6 Mangnall YF, Houghton LA, Johnson AG, Read NW. Abnormal distribution of a fatty liquid test meal within the stomach of patients with non-ulcer dyspepsia. Eur $\mathcal{F}$ stomach of patients with non-ulcer
Gastroenterol Hepatol 1994; 6: 323-7.

7 Wiseman LR, Faulds D. Cisapride. An updated review of its pharmacology and therapeutic efficacy as a prokinetic agent in gastrointestinal motility disorders. Drugs 1994 47: 116-52.

8 Horowitz M, Jones K, Edelbroek MA, Smout AJ, Read NW. The effect of posture on gastric emptying and intragastric distribution of oil and aqueous meal components and appetite. Gastroenterology 1993; 105: 382-90.

9 Cortot A, Phillips SF, Malagelada JR. Parallel gastric emptying of nonhydrolyzable fat and water after a solid-liquid meal in humans. Gastroenterology 1982; 82: 877-81.

10 Meyer JH, Mayer EA, Jehn D, Gu Y, Fink AS, Fried M. Gastric processing and emptying of fat. Gastroenterology 1986; 90: 1176-87.

11 Carney BI, Jones KI, Horowitz M, Sun WM, Penagini R, Meyer JH. Gastric emptying of oil and aqueous meal components in pancreatic insufficiency - effects of posture and on appetite. Am F Physiol 1995; 268: G926-32.

12 Morley JE. Appetite regulation: the role of peptides and hormones. F Endocrinol Invest 1989; 12: 135-47.

13 Bergmann JF, Chassany O, Petit A, Triki R, Caulin C, Segrestaa JM. Correlation between echographic gastric emptying and appetite: influence of psyllium. Gut 1992; 33: 1042-3.

14 Welch IM, Sepple CP, Read NW. Comparison of the effects on satiety and eating behaviour of infusion of lipid into the on satiety and eating behaviour of infusion of lipid into the
different regions of the small intestine. Gut 1988; 29: different

15 Stacher G, Gaupmann G, Mittelbach G, Schneider C, Steinringer H, Langer B. Effects of oral cisapride in interdigestive jejunal motor activity, psychomotor function, and side effect profile in healthy man. Dig Dis Sci 1987; 32: 1223-30.

16 Cunningham KM, Baker RJ, Horowitz M, Maddox AF, Edelbroek MA, Chatterton BE. Use of technetium$99 \mathrm{~m}(\mathrm{~V})$ thiocyanate to measure gastric emptying of fat. $\mathcal{f}$ Nucl Med 1991; 32: 878-81.

17 Collins PJ, Horowitz M, Cook DJ, Harding PE, Shearman DJ. Gastric emptying in normal subjects - a reproducible technique using a single scintillation camera and comtechnique using a single scintillation
puter system. Gut $1983 ; 24: 1117-25$.

18 Sepple CP, Read NW. Gastrointestinal correlates of the development of hunger in man. Appetite 1989; 13: 183-91.

19 Fraser R, Horowitz M, Maddox A, Dent J. Dual effects of cisapride on gastric emptying and antropyloroduodenal motility. Am f Physiol 1993; 264: G195-201.

20 Rezende-Filho J, Di Lorenzo C, Dooley CP, Valenzuela JE Cisapride stimulates antral motility and decreases biliary reflux in patients with severe dyspepsia. Dig Dis Sci 1989; 34: 1057-62.

21 Fraser R, Horowitz M, Maddox A, Dent J. Postprandial antrophyloroduodenal motility and gastric emptying in
gastroparesis - effects of cisapride. Gut 1994; 35: 172-8.

22 Schuurkes JAJ, Akkermans LMA, Van Nueten JM. Stimulating effects of cisapride on antroduodenal motility in the conscious dog. In: Roman C, ed. Gastrointestinal motility. Lancaster: MTP Press, 1983: 95-102.

23 Horowitz M, Dent J. The study of gastric mechanics and flow: a Mad Hatter's tea party starting to make sense? Gastroenterology 1994; 107: 302-6.

24 Maddern GJ, Jamieson GG, Myers JC, Collins PJ. Effect of cisapride on delayed gastric emptying in gastrooesophageal reflux disease. Gut 1991; 32: 470-4.

25 Malbert CH, Mathis C. Antropyloric modulation of transpyloric flow of liquids in pigs. Gastroenterology 1994; 107: 37-46.

26 Malbert $\mathrm{CH}$, Serthelon JP, Dent J. Changes in antroduodenal resistance induced by cisapride in conscious dogs. $\mathrm{Am}$ f Physiol 1992; 263: G202-8.

27 Yox DP, Stokeberry H, Ritter RC. Vagotomy attenuates suppression of sham feeding induced by intestinal nutrisuppression of sham feeding induced by
ents. Am $\Im$ Physiol 1991; 260: R503-8.

28 Gregory PC, McFadyen M, Rayner DV. Duodenal infusion of fat, cholecystokinin secretion and satiety in the pig Physiol Behav 1989; 45: 1021-4.

29 Hausken T, Thune N, Matre K, Ødegaard S, Berstad A Volume estimation of the gastric antrum and gallbladder in patients with non-ulcer dyspepsia and erosive prepyloric changes using three dimensional ultrasonography. Neurogastroenterol Motil 1994; 6: 260-70. 